\title{
Characterisation of FBG based magnetic field sensor response sensitivity to excitation orientation for rotating electric machine applications
}

DOI:

10.1109/MECO.2019.8760181

\section{Document Version}

Accepted author manuscript

Link to publication record in Manchester Research Explorer

Citation for published version (APA):

Durovic, S., Mohammed, A., \& Melecio Ramirez, J. (2019). Characterisation of FBG based magnetic field sensor response sensitivity to excitation orientation for rotating electric machine applications. In IEEE Medditerranean Conference on Embedded Computing IEEE MECO 2019 (pp. 1-4). IEEE.

https://doi.org/10.1109/MECO.2019.8760181

\section{Published in:}

IEEE Medditerranean Conference on Embedded Computing IEEE MECO 2019

\section{Citing this paper}

Please note that where the full-text provided on Manchester Research Explorer is the Author Accepted Manuscript or Proof version this may differ from the final Published version. If citing, it is advised that you check and use the publisher's definitive version.

\section{General rights}

Copyright and moral rights for the publications made accessible in the Research Explorer are retained by the authors and/or other copyright owners and it is a condition of accessing publications that users recognise and abide by the legal requirements associated with these rights.

\section{Takedown policy}

If you believe that this document breaches copyright please refer to the University of Manchester's Takedown Procedures [http://man.ac.uk/04Y6Bo] or contact uml.scholarlycommunications@manchester.ac.uk providing relevant details, so we can investigate your claim.

\section{OPEN ACCESS}




\title{
Characterisation of FBG based magnetic field sensor response sensitivity to excitation orientation for rotating electric machine applications
}

\author{
Juan I. Melecio, Anees Mohammed and Siniša Djurović \\ School of Electrical and Electronic Engineering \\ The University of Manchester \\ Manchester, UK \\ Ignacio.Melecio@manchester.ac.uk,Anees.Mohammed@manchester.ac.uk,Sinisa.Durovic@manchester.ac.uk
}

\begin{abstract}
This paper reports an experimental study aimed at characterising the response of an in-situ fibre optic fibre Bragg grating / magnetostrictive flux sensor when exposed to excitation in orientations aligned with and perpendicular to its optimal performance axes. The study is aimed at improving the understanding of the potential for non-invasive in-situ application of this sensing technology in devices with confined geometries which impose restrictions on possible magnetic excitation axis alignment with that of the sensor, such as those encountered in rotating electric machinery.
\end{abstract}

Keywords - magnetic flux sensing; FBG sensor; Terfenol-D; electric machinery; response characterisation;

\section{INTRODUCTION}

Flux monitoring and analysis in electromagnetic devices, including electric machines, has long attracted interest from performance characterisation and improvement, and diagnostic application perspective [1],[2],[3],[4]. A recently reported flux sensing technique based on utilising a combination of highly magnetostrictive material (Terfenol-D) and fibre-optic fibreBragg grated (FBG) strain sensing has opened new opportunities for in-situ flux monitoring [5],[6],[7]. This is of particular interest for applications in rotary electric machinery, where advanced in-situ monitoring of operational variables including flux can provide potentially useful advantages [1], [8 -13]; the reported applications of FBG based in-situ flux sensing however rely on an invasive implementation technology that may be impractical for large scale use [13]. This is predominantly caused by the nature of conventional radial flux design motor geometries which, in combination with Terfenol-D's anisotropy, impose significant space constraints for application of FBG/Terfenol-D based in-situ flux sensing. There is therefore a need for better understanding of FBG/Terfenol-D flux sensor response features when exposed to magnetic field excitation on different spatial axis within an electric machine representative environment.

This paper undertakes an experimental study with a purpose of mapping the response of FBG/Terfenol-D in-situ flux sensor

This work was supported by the UK Engineering and Physical Sciences Research Council (EPSRC) HOME-Offshore: Holistic Operation and Maintenance for Energy from Offshore Wind Farms Consortium under grant EP/P009743/1). when exposed to excitation from a permanent magnet (PM) motor rotor on the axes aligned with and perpendicular to its axes of anisotropy. To this end a purpose built test rig is developed that employs a commercial surface mounted PM rotor design and a $3 \mathrm{D}$ printed rig support to position the flux sensor in orientations of interest in proximity to the rotor. The assessed positions emulate radial and axial placement of the flux sensor within an assumed electric motor geometry with a view to characterising the possible sensor response in the axial position, where excitation is not aligned with its anisotropy axes, but the machine geometry allows for more space for its installation. A range of experiments are undertaken in both assessed sensor positions at different levels of field dynamics to ascertain the feasibility of axial sensor placement application to monitor rotor PM field distribution.

\section{FBG AND TERFENOL-D BASED FLUX SENSING PRINCIPLES}

\section{A. FBG sensing principles}

FBGs are the periodic gratings on the optical fibre core that result in a periodic modulation of its reflective index when exposed to an interference pattern of laser light [14]. The wavelengths reflected by the FBG structure alter with the variation in the strain and/or temperature it is exposed to, thus enabling the fibre structure to act as a strain and thermal excitation sensitive element; the central wavelength of the reflected light, a small section of the input spectrum, is called the Bragg wavelength $\left(\lambda_{B}\right)$. With an appropriate design, this phenomenon enables the grated fibre to be utilised as a mechanical or thermal sensor. The Bragg wavelength shift due to strain and temperature can be expressed as [15]:

$$
\Delta \lambda_{B}=\lambda_{B}\left[\left(\alpha_{f}+\xi\right) \Delta T+(1-\rho) \Delta_{\varepsilon}\right]
$$

where: $\Delta \lambda_{B}$ is the Bragg wavelength shift, $\lambda_{B}$ is the Bragg central wavelength, $\Delta_{\varepsilon}$ is the applied strain and $\rho$ is the photoelastic coefficient that represents the physical elongation of the fibre; additionally, $\Delta T$ is the temperature variation, $\alpha$ is the fibre thermal expansion coefficient $\left(\approx 0.55 \times 10^{-6} /{ }^{\circ} \mathrm{C}\right)$ and $\xi$ is 
${ }^{8 t h}$ Mediterranean Conference on Embedded Computing ${ }_{1,1}{ }^{1}{ }^{\prime \prime} \mid \quad$ MECO'2019, Budva, Montenegro

the fibre thermo-optic coefficient $\left(\approx 6-9 \times 10^{-6} /{ }^{\circ} \mathrm{C}\right)$ [14]. The effect of temperature is not considered in this work as it is kept constant and variations only due to strain in equation (1) are considered in characterisation tests.

\section{B. Magnetostriction}

Magnetostriction is a phenomenon defined as the change in a material elastic state that accompanies a change in its magnetisation [16]. Magnetic fields cause internal strains in magnetostrictive materials that result in material expansion in the magnetic field direction. The principle magnetostrictive effects can be classified as: Joule (longitudinal only extension), volume (volumetric expansion), Wiedemann (twisting due to helical magnetic field) and form (magnetostatic effect). The Joule effect, which is the expansion or contraction in the same direction as the magnetic field, is the most used phenomenon for the design of actuators or sensors based on magnetostrictive material application [16].

Terfenol-D is among the materials which exhibit the largest known levels magnetostrictive expansion at room temperature. This alloy $\left(T b_{x} D y_{1-x} F e_{y}\right.$, where $y \approx 2.0$ and $\left.x \approx 0.3\right)$ was developed in the 1970 s by the US Naval Ordnance Laboratory and is currently commercially available in a variety of different forms, including thin slices, powder composites and monolith solid samples [13], [17]. When exposed to a magnetic field, Terfenol-D can produce a magnetostrictive extension in the reported range of $800-1200$ parts per million ( $\mathrm{ppm}$ ), which makes it a strong candidate for magnetic sensing applications [17], [18], [19]. Terfenol-D magnetostriction characteristics are a unipolar phenomenon, meaning that positive strain is produced in the presence of either positive or negative magnetic fields. Additionally, the strain output of Terfenol-D is non-linear and while it is generally approximately proportional to the square of the magnetic field it is also highly dependent on the mechanical pre-stress applied to the alloy [17].

\section{FBG/Terfenol-D Magnetostrictive sensor}

The in-situ FBG-magnetostrictive sensor used in this work is designed to study sensing performance in different positions that emulate radial and axial placement of the flux sensor within an assumed electric motor geometry.

To design the in-situ flux sensor, a Terfenol-D piece (TdVib LLC, USA) of rectangular prism geometry with dimensions of $10 \mathrm{~mm}$ (length) x $5 \mathrm{~mm}$ (width) $\mathrm{x} 1 \mathrm{~mm}$ (height) was used with a FBG attached to it to measure strain when the piece is exposed to a magnetic field. The sensor was built by directly bonding the FBG sensing element $(5 \mathrm{~mm})$ in the middle of the rectangular sample piece with a commercial cyanoacrylate glue (Loctite@ Super Glue), as illustrated in Fig.1. In this design, the extreme of the optical fibre carrying the FBG sensing head is packaged in a Teflon tube to provide adequate mechanical protection.

\section{EXPERIMENTAL TEST-RIG DESCRIPTION}

\section{A. Characterised sensor orientations}

The space available to implement an in-situ flux sensor in a non-invasive fashion in conventional electric machine geometries is limited. Therefore, to map the response of an FBG-magnetostrictive flux sensor, an experiment was designed that allows the exposure of the sensor to the machine air-gap field, $\bar{B}$, representative spatial distribution in two different orientations: in position $1, \bar{B}$ is aligned with the sensor axis of anisotropy, while in position $2, \bar{B}$ is perpendicular to its axis of anisotropy. Position 1, radial placement, is the generally preferred position for a magnetostrictive material to be subjected to excitation that yields a maximum strain change; in contrast, the position 2, axial placement, has more potential in enabling practical sensor implementation within the limited space available between the rotor and stator cores of the electric machine. The sensor position orientations are illustrated in Fig.2.

\section{B. Magnetic sensor base design}

In order to experimentally test the flux sensor concept, a 3D printed rig was designed to enable easy handling and positioning of the FBG-Terfenol-D magnetic sensor in Position 1 and 2 under a magnetic field $\bar{B}$. To emulate this field, a PM rotor was used to produce a varying $\bar{B}$. The $3 \mathrm{D}$ printed rig concept equipped with the flux sensor in Position 1 and 2 is shown in Section III.C The assembly rig concept was developed using Inventor Professional by Autodesk@ $@$ which is a commercial 3D CAD modelling software. The design of the assembly rig was conceived to employ a rapid prototyping (RP) plastic material (ABSplus-P430 by Stratasys $($ )), which has sufficient strength to withstand magnetic forces produced by the PM rotor on the sensor assembly. The support rig was fabricated using a Dimension 1200es RP machine by Stratasys $@$ which employs Fused Deposition Modelling (FDM) technology.

\section{Test system description}

The performance of the FBG-Terfenol-D magnetic sensor in positions 1 and 2 was examined in experiments on a laboratory test-rig, whose configuration is shown in Fig.3. A commercial 6-pole surface mounted PM rotor, containing arcshaped PMs, with a pitch of $147\left(\propto_{e}\right)$, was mechanically coupled to a DC motor prime mover whose speed was regulated through a controlled DC power supply.

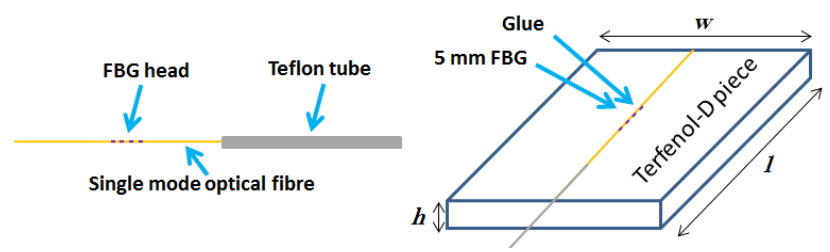

(a)

Figure.1: FBG sensor architecture scheme: (a) FBG strain sensor design, (b) Thin-slice FBG-Terfenol-D magnetic sensor 


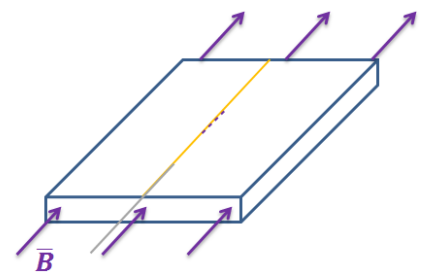

(a)

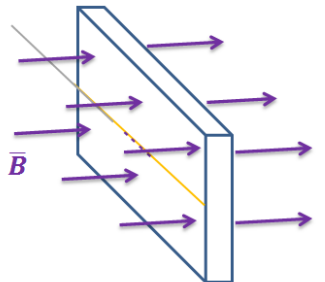

(b)
Figure.2: FBG-Terfenol-D magnetic sensor orientations: (a) position 1(radial placement), parallel to the magnetic field, (b) position 2 (axial placement), perpendicular to the magnetic field

The rig was designed to enable rotation of the PM rotor at desired angular speed and to practically emulate air-gap field distribution, typical of conventional widely used PM electric machines. The purpose designed 3D printed support rig, illustrated in Fig. 4, enables the FBG-Terfenol-D magnetic sensor to be positioned at a desired distance, $d$, from the rotor PMs presenting the source of magnetic field, $\bar{B}$, as shown in Fig.5.

The FBG sensor was illuminated using a broadband light source provided by a commercial multi-channel interrogator unit with a resolution of $1 \mathrm{pm}$. The monitored peak FBG wavelength shift due to the applied magnetic field, related to the strain response of the sensor was processed using the LabVIEW based SmartSoft software.

\section{RESULTS AND DISCUSSION}

The developed test system was applied to evaluate the sensor ability to respond to and register the passage of a rotating magnetic field produced by a PM rotor revolving at a known speed; both position 1 and position 2 performance was assessed in tests in this section. The magnetic flux sensor was mounted on the 3D printed rig so that its FBG sensing head distance from the PM rotor was $6 \mathrm{~mm}$ for both positions. FBG reflected wavelength changes were monitored at 3 different speeds for both positions: $50 \mathrm{rpm}, 500 \mathrm{rpm}$ and $1800 \mathrm{rpm}$. These were chosen to ascertain the sensing performance potential of interest for low speed applications such as wind turbine generators, or in variable speed applications such as electric vehicle propulsion motors [20], [21].

\section{A. Position 1 test results}

The results of the tests at $50 \mathrm{rpm}, 500 \mathrm{rpm}$ and $1800 \mathrm{rpm}$ for the FBG-Terfenol-D magnetic sensor in position 1 (radial placement), are shown in Figs. 6, 8 and 10. As the magnetic field rotates, the resulting Terfenol-D magnetostrictive expansion gives rise to a corresponding variation in the central reflected wavelength of the FBG sensor attached to it; the ensuing strain measurement contains a regular sequence of unipolar positive pulses, where polarity is independent of magnetic field direction, as explained in Section II.B.

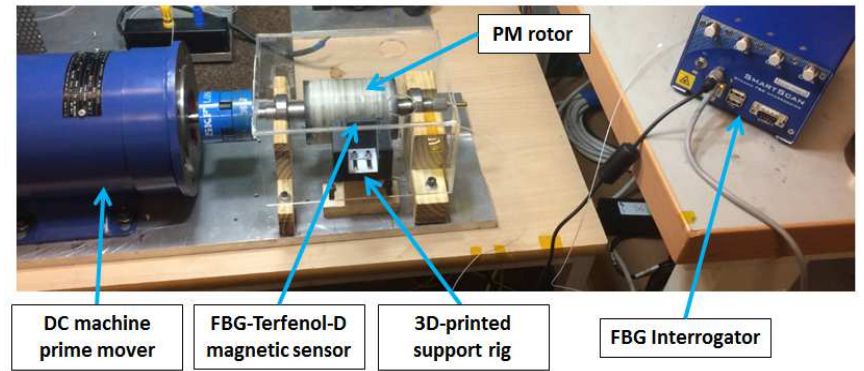

Figure.3: Experimental test rig set-up

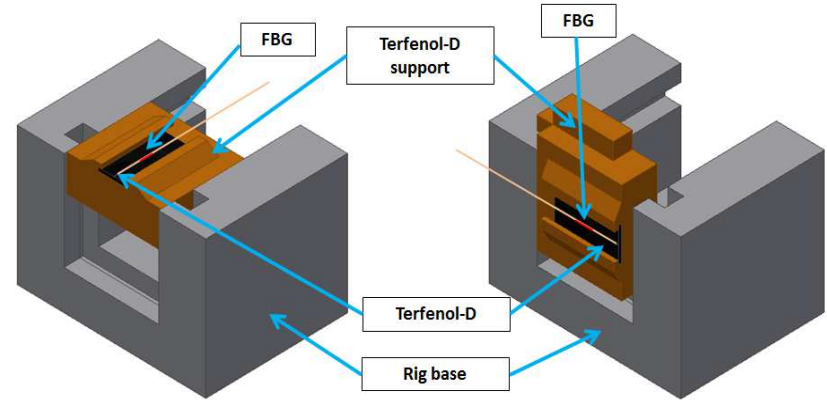

(a)

(b)

Figure.4: 3D printed sensor support rig assembly concept: (a) position 1 (radial placement), (b) position 2 (axial placement)

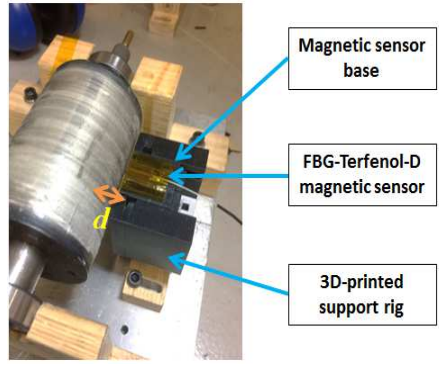

(a)

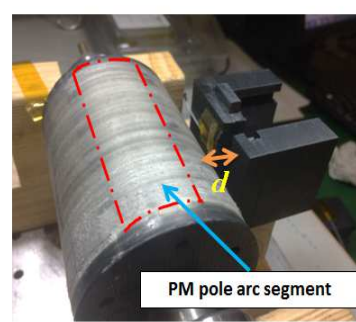

(b)
Figure.5: FBG-Terfenol-D magnetic sensor test-rig aligned with a PM rotor: (a) position 1 (radial placement), (b) position 2 (axial placement)

Figs. 6, 8 and 10 show the recorded signals, clearly containing individual strain pulse measurements that correspond to one magnetic pole movement over the in-situ sensor: monitoring the passage of individual pulses (e.g. rotor poles) in combination with the knowledge of rotor design thus allows the information of the time taken for a mechanical revolution to easily be inferred from the measurement (as illustrated in Fig. 6 for $50 \mathrm{rpm}$ speed and a time window of $0.2 \mathrm{~s}$ ). As rotational speed is increased the sensor is seen to clearly register an increase in measurement frequency. In addition, a further inspection of individual pulse distribution allows for the PM pitch of $\approx 147\left(\propto_{e}\right)$, corresponding to the examined PM rotor design to be identified from flux measurements. 
The results in Figs. 6, 8 and 10 obtained for the sensor's anisotropy axis aligned with the excitation field report the amplitude of the reflected and measure FBG wavelength variation of $\approx 460 \mathrm{pm}$ for the examined cases.

\section{B. Position 2 test results}

The measurements obtained for sensor position 2 are shown in Figs. 7, 9 and 11. Here the magnetic field excitation is not aligned with the sensor's anisotropy axis, but sensing performance is of particular interest for in-situ monitoring applications in electric machinery, as this orientation could allow more space for effective practical incorporation of the sensor geometry into that of the machine.

Figs. 7, 9 and 11 show identical patterns to those that can be observed in the measured data in Figs. 6, 8 and 10: the signals clearly show the peaks of the poles of the PM rotor; as with position 1 based measurements, mechanical revolutions and the PM pitch of $\approx 147\left(\propto_{e}\right)$, can be clearly identified in the recorded data (illustrated in Fig. 9). It is however important to observe a considerable reduction in the amplitude of the observed FBG wavelength reflection in this case compared to results in section IV.A: this is measured at $\approx 70 \mathrm{pm}$ for the identical examined operating conditions. While a reduction in measurement sensitivity is evident, as was generally expected due removing the excitation and sensor alignment applied in

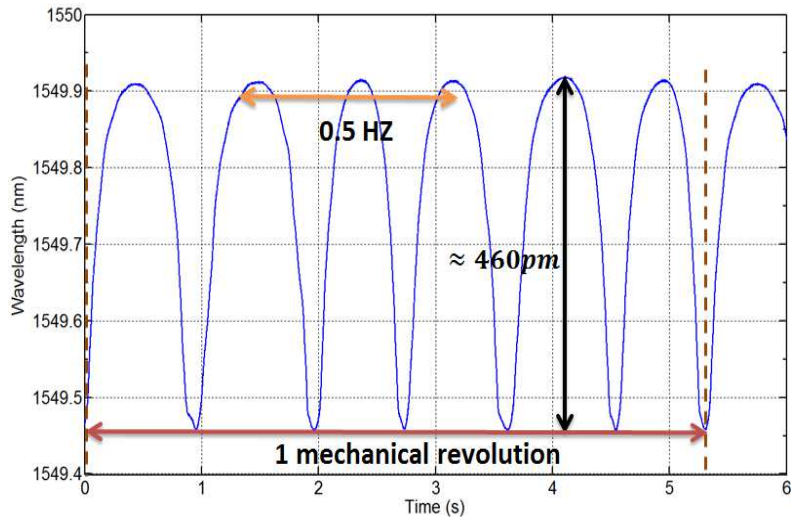

Figure.6: Sensor response in position 1 (radial placement) at $50 \mathrm{rpm}$

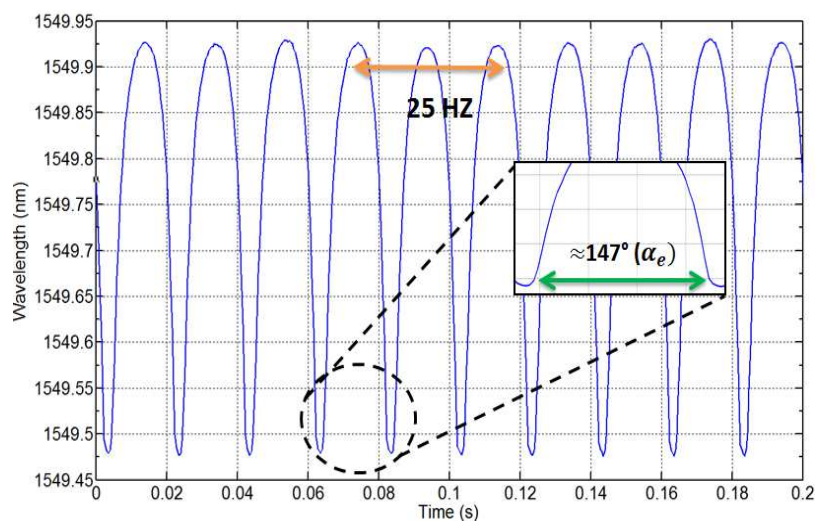

Figure.8: Sensor response in position 1 (radial placement) at $500 \mathrm{rpm}$ position 1 tests, these results show satisfactory potential of the sensor orientation in position 2 for measuring axial strain originating from the magnetic field perpendicular to its anisotropy axis.

\section{Discussion}

The presented results show that the explored flux sensor design is able to consistently measure magnetic field variation and level in both examined positions. A reduction of $85 \%$ of the measured pulses amplitudes is imposed by orienting the sensor in position 2 compared to position 1 performance under the same $\bar{B}$; the measurements however still enable clear understanding of the nature of the observed field distribution indicating no observable loss of diagnostic information.

Additionally, the recorded pulse amplitudes demonstrate the different sensor sensitivity in the two examined orientations. For the case of position 2 , the sensor sensitivity is $\approx 15 \%$ of the sensor sensitivity value at position 1: the sensitivity reduction will in principle impact the resolution of the sensor for any possible in-situ sensing application within an electric motor. This is expected as in position 2, the excitation is not aligned with its anisotropy axis which considerably reduces the sensor response features. However, despite this reduction, position 2 results enable unambiguous identification of magnetic field changes for monitoring purposes.

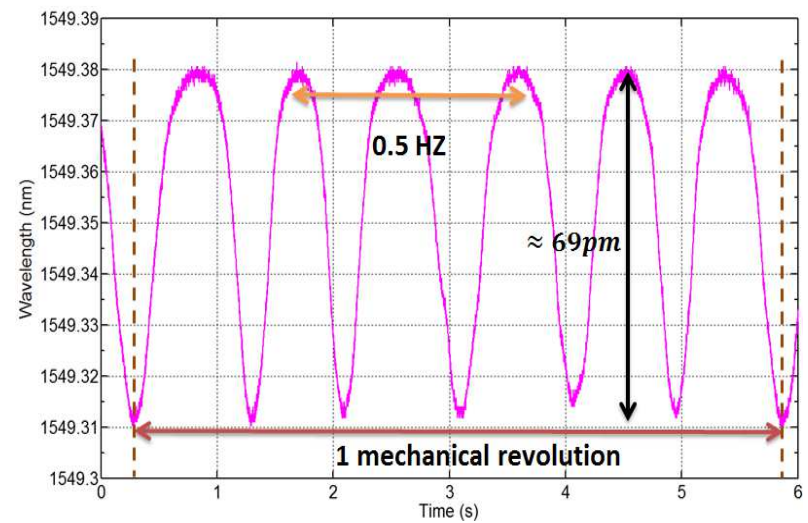

Figure.7: Sensor response in position 2 (axial placement) at $50 \mathrm{rpm}$

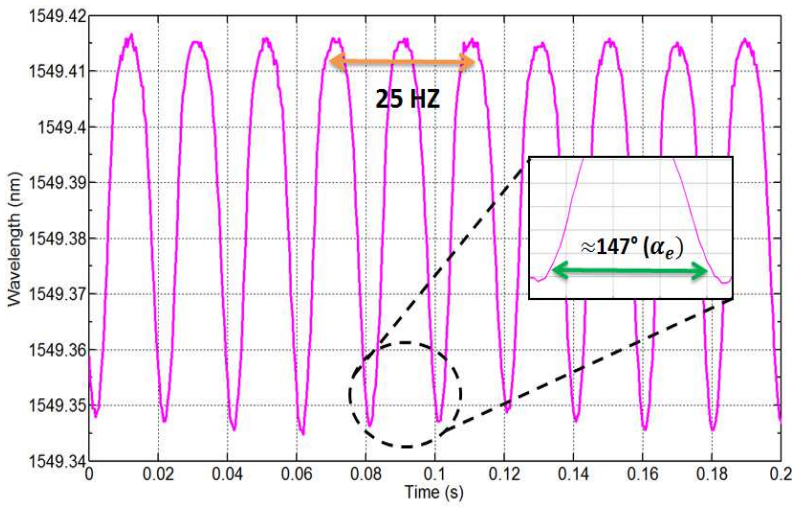

Figure.9: Sensor response in position 2 (axial placement) at $500 \mathrm{rpm}$ 


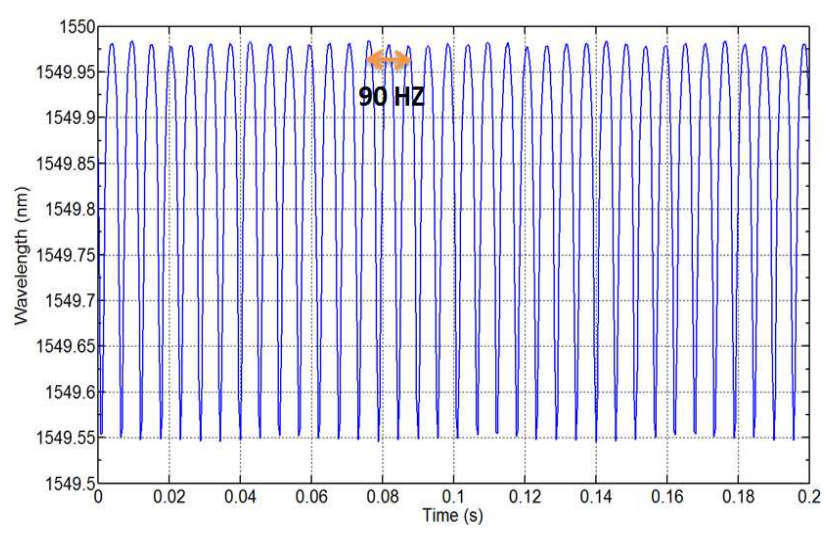

Figure.10: Sensor response in position 1 (radial placement) at $1800 \mathrm{rpm}$

\section{CONCLUSION}

This paper presents an experimental study aimed at mapping the response of an FBG/Terfenol-D in-situ flux sensor when exposed to excitation from a permanent magnet (PM) motor rotor on the axes aligned with and perpendicular to its axes of anisotropy at different operating speeds. The obtained results indicate that the sensor can clearly detect field passage when positioned so that its anisotropy axis is perpendicular to excitation produced by a PM rotor - while the reported measurements suffer an $\approx 85 \%$ reduction in amplitude in this case, they also retain the information on the observed flux distribution and are shown to contain comparable levels of usability for monitoring purposes to those attained when the sensor is aligned with the excitation field.

The presented results provide a further insight into opportunities for application of this sensing technology in confined areas available within electric motor geometries. While at a fundamental level, the presented concept could enable useful advances in development of non-invasive in-situ monitoring schemes; its practical development and implementation within operating machinery will be the subject of further studies.

\section{REFERENCES}

[1] P. J. Tavner, "Review of condition monitoring of rotating electrical machines," in IET Electric Power Applications, vol. 2, no. 4, pp. 215247, July 2008.

[2] S. Nandi, H. A. Toliyat and X. Li, "Condition Monitoring and Fault Diagnosis of Electrical Motors-A Review," in IEEE Transactions on Energy Conversion, vol. 20, no. 4, pp. 719-729, Dec. 2005.

[3] C. Jiang, S. Li and T. G. Habetler, "A review of condition monitoring of induction motors based on stray flux," 2017 IEEE Energy Conversion Congress and Exposition (ECCE), Cincinnati, OH, 2017, pp. 5424-5430.

[4] P. M. Tuohy, S. Djurović and A. C. Smith, "Finite element analysis of winding fault effects in a wound-rotor induction machine with experimental validation," 6th IET International Conference on Power Electronics, Machines and Drives (PEMD 2012), Bristol, 2012, pp. 1-6.

[5] Mingfan Li, Jinfang Zhou, Zhanqin Xiang and Fuzai Lv, "Giant magnetostrictive magnetic fields sensor based on dual fiber Bragg gratings," Proceedings. 2005 IEEE Networking, Sensing and Control, 2005., Tucson, AZ, 2005, pp. 490-495.

[6] C. Ambrosino, S. Campopiano, A. Cutolo and A. Cusano, "Sensitivity Tuning in Terfenol-D Based Fiber Bragg Grating Magnetic Sensors," in IEEE Sensors Journal, vol. 8, no. 9, pp. 1519-1520, Sept. 2008.

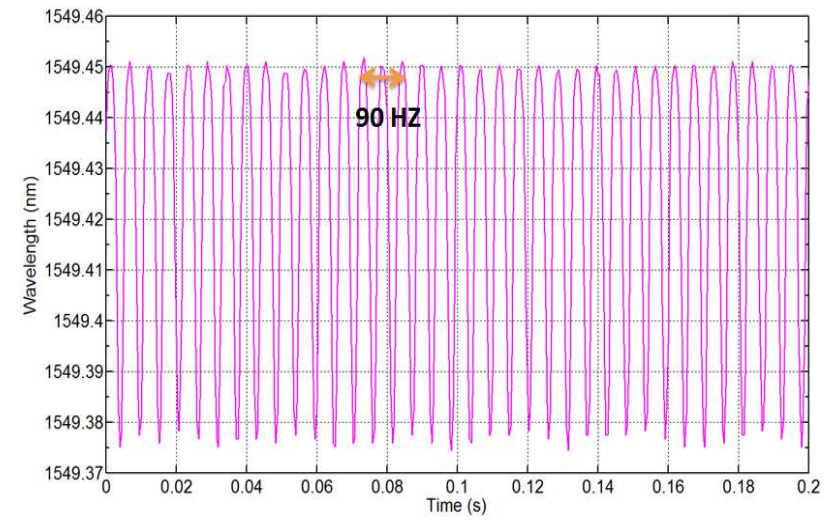

Figure.11: Sensor response in position 2 (axial placement) at $1800 \mathrm{rpm}$

[7] D. Davino, C. Visone, C. Ambrosino, S. Campopiano, A. Cusano, A. Cutolo,"Compensation of hysteresis in magnetic field sensors employing Fiber Bragg Grating and magneto-elastic materials", Sensors and Acutators A 147 (2008), 127-136.

[8] Khalid Saad, Galina mirzaeva, "Fault diagnostics of induction motors based on internal flux measurement", 2014 IEEE International Conference on Industrial Technology (ICIT), Busan Korea, 2014.

[9] A. A. Mohammed, J. I. Melecio and S. Djurovic, "Stator Winding Fault Thermal Signature Monitoring and Analysis by in situ FBG sensors," in IEEE Transactions on Industrial Electronics, doi: 10.1109/TIE.2018.2883260.

[10] A. Mohammed and S. Djurović, "Stator Winding Internal Thermal Monitoring and Analysis Using In Situ FBG Sensing Technology," in IEEE Transactions on Energy Conversion, vol. 33, no. 3, pp. 1508-1518, Sept. 2018.

[11] A. Mohammed, J. I. Melecio and S. Djurović, "Open-Circuit Fault Detection in Stranded PMSM Windings Using Embedded FBG Thermal Sensors," in IEEE Sensors Journal, vol. 19, no. 9, pp. 3358-3367, 1 May1, 2019.

[12] A. Mohammed, N. Sarma and S. Djurović, "Fibre optic monitoring of induction machine frame strain as a diagnostic tool," 2017 IEEE International Electric Machines and Drives Conference (IEMDC), Miami, FL, 2017, pp. 1-7.

[13] Gerardo Bieler, Marcelo M. Werneck, "A magnetostrictive-fiber Bragg grating sensor for induction motor health monitoring", in Measurement Journal, 2018, 52, pp.117-127.

[14] Rao, Yun-Jiang, "In-fibre Bragg grating sensors," Measurement science and technology 8.4 (1997): 355.

[15] Werneck, M.M.; Allil, R.; Ribeiro, B.; de Nazaré, F. A guide to fiber Bragg grating sensors. In Current Trends in Short-and Long-Period Fibre Gratings", in InTech. Rijeka, Croatia, 2013; pp. 1-24.

[16] G. Engdahl, Ed., Handbook of Giant Magnetostrictive Materials. New York: Academic, 2000.

[17] Terfenol-D, "Physical Properties", http://tdvib.com/terfenol-d/, 2019.

[18] E. Hristoforou and A. Ktena, "Magnetostriction and magnetostrictive materials for sensing applications," J. Magnetism and. Magnetic Materials., vol. 316, no. 2, pp. 372-378, Sep. 2007.

[19] N. B. Ekreem, a. G. Olabi, T. Prescott, a. Rafferty, and M. S. J. Hashmi, "An overview of magnetostriction, its use and methods to measure these properties," J. Mater. Process. Technol., vol. 191, no. 1-3, pp. 96-101, Aug. 2007.

[20] Automotive Council UK. Advanced Propulsion Centre UK. www.apcuk.co.uk/app/uploads/2018/02/EMC_Full_Pack.pdf

[21] B. Sarlioglu, C. T. Morris, D. Han and S. Li, "Driving Toward Accessibility: A Review of Technological Improvements for Electric Machines, Power Electronics, and Batteries for Electric and Hybrid Vehicles," in IEEE Industry Applications Magazine, vol. 23, no. 1, pp. 14-25, Feb. 2017. 